\section{RELATIONSHIP BETWEEN CARDIAC RHABDOMYOMAS AND TUBEROUS SCLEROSIS COMPLEX}

H.S. Eun, R. Namgung, M.S. Park, K.I. Park, C. Lee

Pediatrics, Severance Children's Hospital, Yonsei University College of Medicine, Seoul, Republic of Korea

TSC is an autosomal dominant disorder characterized by widespread harmatomas, usually occurring in the brain, eyes, skin, kidney, liver, heart and lungs, resulting in a variable clinical manifestation. Rhabdomyomas is most common cardiac tumor to be detected on fetal US. The detection of a rhabdomyoma is maybe useful for a prenatal diagnosis of TSC.This study is aimed to examine whether prenatally diagnosed cardiac rhabdomyomas is associated with TSC.We conducted a 4-year (2005 to2009) retrospective review of all children diagnosed with cardiac rhabdomyoma. Medical records were systemically reviewed for demographic date, age of diagnosis, initial presenting features, major criteria identified by time of diagnosis. Reports of postnatal CT and MRI scans were reviewed to determine the presence and extent of brain pathology. Diagnosis was based on the clinical diagnostic criteria, which was revised at TSC consensus conference in 1998.

Nine presented with a cardiac rhabdomyoma. Five $(55 \%)$ received a definitive diagnosis and had radiographic evidence of cortical tubers. Four(80\%) had multiple lesion and one $(20 \%)$ had single cardiac lesion. One(20\%) presented with seizure at the time of diagnosis and presented with facial angioma. Two(40\%) presented with retinal nodule. Three was performed TSC2 gene study and two(40\%) was confirmed the diagnosis of TSC. This study suggests that cardiac rhabdomyoma and cortical tuber in the fetus are the earliest and the most frequent reported signs of TSC. Although cardiac rhabdomyoma was the only symptom of TSC in the patient, we performed further diagnostic evaluation and genetic counseling.

\section{THE SURVIVAL RATE AND EARLY MORBIDITY OF VLBW NEWBORNS DURING THE YEARS 2006-2009 IN A SINGLE NICU IN GREECE}
A. Tsantila, A. Konstantinidi, V. Makri,
P. Panagiotounakou, M. Papadopoulou,
M. Theodoraki, I. Labadaridis, A. Gounaris

NICU and Neonatology Department of General Hospital of Nikea, Piraeus «Agios Panteleimon,

Piraeus, Greece

The morbidity and mortality rates of very premature infants are essential for prenatal counseling and quality control.

Methods: We reviewed all infants with $\mathrm{GA}<32$ w and $B W<1500$ gr admitted during the years 2006-2009 to a single neonatal intensive care unit.

Results: The survival rate until hospital discharge for infants admitted to NICU and early morbidity are shown in table 1 and 2.

Table 1.The survival rate(\%) during the years 2006 2009

\begin{tabular}{|l|l|l|l|l|}
\hline & 2006 & 2007 & 2008 & 2009 \\
\hline $\begin{array}{l}500- \\
1000 \mathrm{gr}\end{array}$ & 73.7 & 83.4 & 88.9 & 94.1 \\
\hline$<1500 \mathrm{gr}$ & 86.7 & 90 & 93.9 & 94.7 \\
\hline $24-31 \mathrm{w}$ & 82 & 89.7 & 93.2 & 94.7 \\
\hline
\end{tabular}

[Table 1]

Table 2.The morbidity (\%) during the years 20062009

\begin{tabular}{|l|l|l|l|l|}
\hline & 2006 & 2007 & 2008 & 2009 \\
\hline $\begin{array}{l}\text { PDA(surg. } \\
\text { ligam.) }\end{array}$ & 13.3 & 14.2 & $20.8(4.2)$ & 15.7 \\
\hline $\begin{array}{l}\text { IVH III-IV } \\
\text { (hydrocep.) }\end{array}$ & $11(6.6)$ & $\begin{array}{l}14.2 \\
(3.6)\end{array}$ & $4.2(2.1)$ & 7.9 \\
\hline $\begin{array}{l}\text { NEK stage } \\
\text { I (II) }\end{array}$ & 2.2 & 3.6 & $18.7(2)$ & $2.6(2.6)$ \\
\hline ROP (laser) & $16.6(4.7)$ & $\begin{array}{l}17.8 \\
(14.2)\end{array}$ & $12.5(6.7)$ & $18.4(7.9)$ \\
\hline BPD & 38 & 39.3 & 39.5 & 55.2 \\
\hline PVL & 35.7 & 39.3 & 39.5 & 44.7 \\
\hline
\end{tabular}

[Table 2]

Conclusions: We found improvement in survival rate between the year 2006 and 2009 in the study group. It seems an increased incidence in bronchopulmonary dysplasia and in periventricular leukomalacia the last year maybe due to increased survival rate. 